\title{
Viral Diarrhoea in Children of Dhulikhel Hospital, Nepal and Medical University of Innsbruck, Austria
}

\author{
Anish Joshi*, Ranendra Prakash Bahadur Shrestha
}

Affiliations:

Department of Pediatrics, Dhulikhel Hospital/Kathmandu University Hospital, Dhulikhel, Nepal

Correspondence to:

Dr. Anish Joshi

Lecturer/Pediatrician

Department of Pediatrics

Dhulikhel Hospital/Kathmandu University Hospital

Dhulikhel, Nepal.

Email: anishjoshi2001@yahoo.com

How to cite this article:

Joshi A, Shrestha R P B. Viral Diarrhoea in Children of Dhulikhel Hospital, Nepal and Medical University of Innsbruck, Austria. Ann. Clin. Chem. Lab. Med. 2016:2(1);11-18

DOI: http://dx.doi.org/10.3126/acclm.v2i1.13769

(C) 2016 Nepalese Association for Clinical Chemistry

\section{(c) (1) (1)}

This work is licensed under a Creative Commons Attribution-ShareAlike 4.0 International License.
Abstract

BACKGROUND

Viral diarrhoea is still a major cause of childhood morbidity and mortality worldwide, with high morbidity in children younger than 5 years of age particularly in developing countries. The objective of this study was to determine the frequency of viral diarrhoea in children less than 5 years of age at Kathmandu University Hospital/Dhulikhel Hospital (DH), Nepal and Medical University of Innsbruck (MUI), Austria and to compare the clinical presentation and the common cause of acute childhood diarrhoea in the two institutions.

\section{METHODS}

This was a hospital based, comparative study done in two different hospitals DH and MUI. A total of 200 cases of under 5 years old children, among which 100 cases attending DH from $1^{\text {st }}$ December 2011 to $29^{\text {th }}$ February 2012 and 100 cases attending MUI from $1^{\text {st }}$ March 2012 to $31^{\text {st }}$ May 2012, presented with acute onset of diarrhoea were enrolled in the study. The fresh stool specimens were analysed in the laboratory of individual hospital in order to examine the common pathogens.

\section{RESULTS}

Majority of children were classified as no dehydration (DH: 75\% and MUI: 74\%); in DH 5\% were classified as severe dehydration, whereas in MUI it was null. In MUI, 96\% of children were brought within 3 days of illness, whereas only $32 \%$ were brought in $\mathrm{DH}$ which was statistically significant $(p=<0.001)$. In DH $37 \%$ of cases required hospital admission, among which 7 cases needed PICU, whereas in MUI, $52 \%$ of cases were admitted $(\mathrm{p}=0.03)$; and no cases needed PICU. The mean hospital stay was $1.1 \pm 1.7$ days and $1.3 \pm 1.8$ days in $\mathrm{DH}$ and MUI, respectively. Rotavirus was positive in significant number of cases in DH (66\%) $(\mathrm{p}=<0.001)$. Other pathogen detected in $\mathrm{DH}$ was Adenovirus (13\%). The most common pathogen detected in MUI was Norovirus (16\%), followed by Rotavirus (11\%) and Adenovirus (9\%).

\section{CONCLUSIONS}

Incidence of acute diarrhoea was highest below 24 months of age. Rotavirus and Norovirus was the most common cause of children diarrhoea in Nepal and Austria, respectively.

KEYWORDS: Children, diarrhoea, dehydration, Rotavirus 


\section{Introduction}

Diarrhoea is a clinical syndrome of diverse etiology, associated with passage of more than three loose stools in a 24 hours period and often accompanied by other clinical sign and symptoms including vomiting, fever, dehydration and electrolyte disturbances [1]. Diarrhoea is a major health problem among children. In addition, it remains a major cause of childhood morbidity and mortality worldwide [2]. The highest mortality from diarrhoea is in children under the age of five, highlighting an urgent need for focused interventions to prevent diarrhoeal disease in this age group [3]. Five million children under the age of 2 years die from diarrhoeal disease in developing countries each year and Rotavirus infections account for about $20 \%$ of these deaths [4]. Nepal, being a developing country, faces similar health problem as other developing countries; Diarrhoea and gastroenteritis come in second position among top ten diseases admitted to hospital [5]. In industrialised countries, mortality rates associated with Rotavirus gastroenteritis are low, but Rotavirus remains a significant paediatric disease, responsible for hospitalisation and nosocomial infection in many children $[6,7]$. Norovirus causes 900,000 clinical visits in industrialized countries and up to 200,000 deaths in children from developing countries [8].

Inappropriate environmental condition and weak economical status are the important risk factors of acute diarrhoea. Worldwide diarrhoea related mortality has decreased, mainly because of better therapeutic interventions along with provision of safe drinking water, improvement of sanitation and popularization of primary health care activities [9]. In Nepal, due to lower socioeconomic status and poor hygienic condition of the people, intestinal parasitosis is very much prevalent and intestinal pathogens are important causative agents of diarrhoea and are one of the major public health problems of the country [10].

This study undertook prospective diarrhoeal surveillance among children less than 5 years of age presenting in DH and MUI. Since DH is the only tertiary level health care centre in the district, majority children of the vulnerable section of population suffering from diarrhoea and other illness are likely to attain this hospital. After pneumonia, diarrhoea is the second commonest cause of infection related disease among under 5 years children admitted in $\mathrm{DH}$. The result of this study is expected to encourage the health care professionals in terms of diagnosis and treatment plan of childhood diarrhoea. The primary objective of this study was to assess and compare the frequency and clinical characteristics of childhood diarrhoea, diarrhoea severe enough to bring a child to medical attention. We expect that these results will also be useful to think about vaccine requirements in a developing country like Nepal.

\section{Methods}

This hospital based, prospective, noninterventional, comparative study was carried out in two different hospitals at Kathmandu University Hospital/Dhulikhel Hospital (DH), Nepal and at Medical University of Innsbruck (MUI), Austria, Department of Paediatrics.

In $\mathrm{DH}$ data were collected from 1st December 2011 to 29th February 2012, In MUI data were collected from 1st March 2012 to 31st May 2012.

Children under 5 years of age presented with acute onset of diarrhoea with or without nausea and vomiting attending in outpatient, emergency and those admitted in inpatient department were enrolled in the study with purposive sampling technique. Children with dysentery, newborns less than 28 days, children with persisting diarrhoea more than 14 days and children with other associated chronic disease were excluded.

Total sample collected was 200 (100 cases from $\mathrm{DH}$ and 100 cases from MUI).

The definition of diarrhoea, dehydration status and its management was assessed and classified according to the guidelines of the World Health Organization (WHO), which is followed in the Integrated Management of Childhood Illness (IMCI) training.

Mild, moderate and severe fever was defined as a rectal temperature of $37.7{ }^{0} \mathrm{C}-38.5{ }^{\circ} \mathrm{C}, 38.6{ }^{\circ} \mathrm{C}$ $-39.5^{\circ} \mathrm{C}$ and $>39.5{ }^{\circ} \mathrm{C}$ respectively.

If an organism was identified from the stool sample, the child was classified as "infected" with that organism. "Undiagnosed diarrhoea" included any episode in which a studied virus was undetected.

All the 200 stool specimens were analysed in the respective hospital laboratories. One faecal specimen was collected from each patient; freshly passed stool samples were collected in clean plastic containers. All the samples were examined within 2 hours of collection. The specimen was subjected to naked eye examination for 
consistency, colour, and atypical components (mucus, blood and parasites). Following the manufacturer's instructions the CerTest RotaAdeno Card (Biotec, Zaragoza, Spain), an immunochromatographic test for Rotavirus and Adenovirus detection in stool specimens was used for routine testing. The sensitivity for Rotavirus and Adenovirus detection of this test system is $100 \%$ and $90 \%$ respectively, and the specificity for Rotavirus and Adenovirus detection of this test system is $99 \%$ and $100 \%$ respectively $[11,12]$. All the stool samples were collected in clean containers and the assay done right after collection. The samples were stored in the refrigerator $\left(2-4^{0} \mathrm{C}\right)$ for 1 day if the test were to be conducted the next day. The samples were brought to room temperature before the tests. In MUI all the stool specimens were also tested for Norovirus using similar ELISA kits (CerTest Rota-Adeno-Noro Card, Biotec, Zaragoza, Spain). Due to lack of facility and financial constraint stool specimens for Norovirus could not be tested in $\mathrm{DH}$.

Data was entered and analysed using SPSS (Statistical Package for Social Science) version 20. Data analysis was done using both descriptive (mean and percentage) and inferential $\left({ }^{2} 2\right.$ test) statistics. Statistical test was considered significant at 0.05 level of confidence.

The research proposal was submitted to the Ethical Review Board of Kathmandu University School of Medical Sciences for approval. A written informed consent from parents or guardians of the enrolled child was taken prior to participation and stool collection for the study.

For the research purpose ELISA kits used for the detection of Rotavirus and Adenovirus antigen in DH were provided by MUI, Department of Microbiology. No financial burden was incurred to patient's expense, except for routine stool examination and routine charges as per hospital policy.

\section{Results}

A total of 200 cases of under 5 years old children, among which 100 cases attending DH from $1^{\text {st }}$ December 2011 to $29^{\text {th }}$ February 2012, and 100 cases attending MUI from $1^{\text {st }}$ March 2012 to $31^{\text {st }}$ May 2012, fulfilling the inclusion criteria and whose parents gave consent to participate in the study were enrolled and studied. During this different study period, total of 274 and 101 under five years old children with diarrhoea attended DH and MUI respectively.
Majority of the study population were in the age group of 1 month to 12 months in both $\mathrm{DH}$ (48\%) and MUI (45\%). Children less than 24 months occupied $77 \%$ and $73 \%$ of the study population in DH and MUI respectively.

The mean age was 17.6 months $(S . D \pm 14.4$ months) and 20.7 months (S.D \pm 18.1 months) in DH and MUI respectively. Out of 100 children studied in each institution 69\% were males and $31 \%$ were females in $\mathrm{DH}$, whereas $53 \%$ were males and $47 \%$ were females in MUI. Although male children were seen to suffer more from diarrhoea in $\mathrm{DH}$, this difference in sex was not statistically significant.

Majority of stool samples tested positive for Rotavirus (66\%) and Adenovirus (13\%) in DH. Stools were not tested for Norovirus in $\mathrm{DH}$. Similarly, stool was tested positive for Norovirus (16\%), Rotavirus (11\%), and Adenovirus (9\%) in MUI.

Rotavirus was detected in significantly high number of cases in DH (66\%), whereas only $11 \%$ of cases were detected in MUI $(\mathrm{p}=<0.001)$.

Comparing infected cases with age of the children in $\mathrm{DH}$, more than $78 \%$ (52 cases) of Rotavirus positive cases were below 24 months of age $(p=0.7)$, similarly more than $69 \%$ (9 cases) of Adenovirus positive cases were below 24 months of age $(p=0.4)$. The mean age of Rotavirus positive case and Adenovirus positive case was 16.3 months and 19.7 months respectively.

Comparing infected cases with age of the children in MUI, 75\% (12 cases) of Norovirus positive cases were below 24 months of age ( $p=0.8$ ), more than $54 \%$ (6 cases) of Rotavirus positive cases were below 24 months of age $(p=0.1)$, similarly more than $88 \%$ (8 cases) of Adenovirus positive cases were below 24 months of age $(p=0.2)$. The mean age of Norovirus, Rotavirus and Adenovirus positive case was 21.8 months, 27.0 months and 29.1 months respectively.

Comparing between the diarrheal cases in $\mathrm{DH}$ and MUI, significantly $96 \%$ of children were brought within 3 days of illness in MUI, whereas only $32 \%$ were brought within 3 days of illness in $\mathrm{DH}$ which shows that parents are seeking for medical service in MUI significantly earlier than in $\mathrm{DH}(\mathrm{p}=<0.001)$ [Table 1].

The mean duration of illness prior presentation to hospital was $3.2 \pm 1.5$ days and $1.7 \pm 1.1$ days in $\mathrm{DH}$ and MUI respectively. 
Table 1. Correlation of clinical parameters between DH and MUI

\begin{tabular}{lccc}
\hline & $\begin{array}{c}\mathrm{DH} \\
\mathrm{n}=100\end{array}$ & $\begin{array}{c}\text { MUI } \\
\mathrm{n}=100\end{array}$ & $\begin{array}{c}\mathrm{p}- \\
\text { value }\end{array}$ \\
\hline $\begin{array}{l}\text { Age ( } \leq 24 \text { months) } \\
\begin{array}{l}\text { Duration of illness } \\
\text { prior presenting to }\end{array}\end{array}$ & 77 & 73 & 0.5 \\
$\begin{array}{l}\text { hospital ( } \leq 3 \text { days) } \\
\text { History of fever }\end{array}$ & 36 & 36 & 0.001 \\
$\begin{array}{l}\text { Dehydration } \\
\text { Hospital admission }\end{array}$ & 25 & 26 & 0.3 \\
\hline
\end{tabular}

In $\mathrm{DH} 97 \%$ of Rotavirus positive cases had duration of illness prior presentation to hospital of less than 6 days with the maximum of 9 days in 1 case, whereas all Adenovirus positive cases were brought within 6 days of illness, with the maximum of 6 days in 1 case. The mean duration of illness for Rotavirus and Adenovirus positive cases prior presenting to the hospital were 3.2 days and 2.9 days, respectively.

In MUI all the Norovirus, Rotavirus and Adenovirus positive cases were brought to the hospital within 3 days of illness. The maximum duration of illness prior presentation to hospital for Norovirus, Rotavirus and Adenovirus positive cases were 3 days, 2 cases in each. The mean duration of illness prior presenting to hospital for Norovirus, Rotavirus and Adenovirus positive cases were 1.62 days, 1.63 days and 2.0 days, respectively.

The majority had no history of fever in both the institutions (DH 64\% and MUI 70\%). Comparing children having history of fever $(\mathrm{DH}$ 36 cases and MUI 30 cases) with their age group, more than $77 \%$ (28 cases) and $80 \%$ (24 cases) of children having history of fever were below 24 months of age in DH ( $\mathrm{p}=0.9)$ and MUI $(\mathrm{p}=0.3)$ respectively. Although the majority of children having fever with diarrhoea were below 24 months in both the institutions, this difference was statistically not significant.

Out of the 66 Rotavirus positive cases in $\mathrm{DH}$, more than $62 \%$ (41 cases) had no history of fever $(\mathrm{p}=0.5)$, whereas among the 13 Adenovirus positive cases more than 69\% (9 cases) had history of fever $(\mathrm{p}=0.01)$.

Out of the 16 Norovirus positive cases in MUI, $50 \%$ (8 cases) had history of fever $(\mathrm{p}=0.07)$. Similarly, out of 11 Rotavirus positive cases more than $81 \%$ ( 9 cases) had history of fever $(\mathrm{p}=0.0001)$. However, out of 9 Adenovirus positive cases more than $88 \%$ (8 cases) had no history of fever $(\mathrm{p}=0.2)$.

Among all the 100 children assessed in each institutions majority were classified as no dehydration in both the institutions (DH 75\% and MUI 74\%). In DH 20\% were classified as some dehydration and $5 \%$ as severe dehydration, whereas in MUI 26\% were classified as some dehydration; however, there were no cases of severe dehydration in MUI.

Comparing children having dehydration (DH 25 cases and MUI 26 cases) with their age group, $80 \%$ (20 cases) and 84\% (22 cases) of children having some form of dehydration was found to be below 24 months of age in $\mathrm{DH}(\mathrm{p}=0.7)$ and MUI $(p=0.1)$ respectively. The mean age of some dehydration was 14.8 months and 16.2 months in DH and MUI respectively.

Table 2. Relation between infected cases with signs of dehydration in DH and MUI.

\begin{tabular}{|c|c|c|c|}
\hline Infection & Yes & No & p-value \\
\hline \multicolumn{4}{|l|}{$\mathrm{DH}$} \\
\hline $\begin{array}{l}\text { Rotavirus (+) } \\
\mathrm{n}=66\end{array}$ & $\begin{array}{c}15 \\
(22.7 \%)\end{array}$ & $\begin{array}{c}51 \\
(77.3 \%)\end{array}$ & 0.4 \\
\hline $\begin{array}{l}\text { Adenovirus (+) } \\
\mathrm{n}=13\end{array}$ & $\begin{array}{c}2 \\
(15.4 \%) \\
\end{array}$ & $\begin{array}{c}11 \\
(84.6 \%) \\
\end{array}$ & 0.5 \\
\hline \multicolumn{4}{|l|}{ MUI } \\
\hline $\begin{array}{l}\text { Norovirus }(+) \\
\mathrm{n}=16\end{array}$ & $\begin{array}{c}8 \\
(50.0 \%)\end{array}$ & $\begin{array}{c}8 \\
(50.0 \%)\end{array}$ & 0.02 \\
\hline $\begin{array}{l}\text { Rotavirus (+) } \\
\mathrm{n}=11\end{array}$ & $\begin{array}{c}6 \\
(54.5 \%)\end{array}$ & $\begin{array}{c}5 \\
(45.5 \%)\end{array}$ & 0.03 \\
\hline $\begin{array}{l}\text { Adenovirus }(+) \\
\mathrm{n}=9\end{array}$ & $\begin{array}{c}5 \\
(55.6 \%) \\
\end{array}$ & $\begin{array}{c}4 \\
(44.4 \%) \\
\end{array}$ & 0.2 \\
\hline
\end{tabular}

Comparing infected cases with clinical signs of dehydration in $\mathrm{DH}$, more than $77 \%$ (51 cases) of Rotavirus positive cases had no signs of dehydration $(\mathrm{p}=0.4)$, similarly more than $84 \%$ (11 cases) of Adenovirus positive cases had no signs of dehydration $(\mathrm{p}=0.5)$ [Table 2].

Comparing infected cases with clinical signs of dehydration in MUI, 50\% (8 cases) Norovirus positive cases had signs of dehydration $(\mathrm{p}=0.02)$; similarly, more than $54 \%$ (6 cases) of Rotavirus positive cases had signs of dehydration $(\mathrm{p}=0.03)$; and more than $55 \%$ (5 cases) of Adenovirus positive cases had signs of dehydration $(p=0.2)$ [Table 2].

Among the 100 cases with diarrhoea in each institution, in DH 37\% of cases needed hospital admission among which 7 cases needed PICU care; In MUI $52 \%$ of cases needed hospital admission which was significantly higher in comparison to hospital admission in $\mathrm{DH}$ $(\mathrm{p}=0.03)$. However, no cases needed PICU care in MUI. There were no mortality due to diarrhoea within the study period in either of the institutions. 
Comparing between admitted cases (DH 37 cases and MUI 52 cases) with their age group, $81.1 \%$ (30 cases) and 78\% (41 cases) were below 24 months of age in DH $(\mathrm{p}=0.5)$ and MUI $(\mathrm{p}=0.1)$ respectively.

Comparing between the hospital admitted and infected cases in $\mathrm{DH}$, among the 66 Rotavirus positive cases $36.4 \%$ (24 cases) needed hospital admission ( $\mathrm{p}=0.8$ ) and among 13 Adenovirus positive cases $46.2 \%$ (6 cases) needed hospital admission ( $\mathrm{p}=0.5)$ [Table 3].

Table 3. Correlation between infected cases with inpatient and outpatient care in DH and MUI

\begin{tabular}{|c|c|c|c|}
\hline Infection & Inpatient & Outpatient & p-value \\
\hline \multicolumn{4}{|l|}{ DH } \\
\hline $\begin{array}{l}\text { Rotavirus (+) } \\
\mathrm{n}=66\end{array}$ & $24(36.4 \%)$ & $42(63.6 \%)$ & 0.8 \\
\hline $\begin{array}{l}\text { Adenovirus (+) } \\
\mathrm{n}=13\end{array}$ & $6(46.2 \%)$ & $7(53.8 \%)$ & 0.5 \\
\hline \multicolumn{4}{|l|}{ MUI } \\
\hline $\begin{array}{l}\text { Norovirus (+) } \\
\mathrm{n}=16\end{array}$ & $11(68.8 \%)$ & $5(31.2 \%)$ & 0.1 \\
\hline $\begin{array}{l}\text { Rotavirus (+) } \\
\mathrm{n}=11\end{array}$ & $10(90.9 \%)$ & $1(9.1 \%)$ & 0.006 \\
\hline $\begin{array}{l}\text { Adenovirus (+) } \\
\mathrm{n}=9\end{array}$ & $9(100.0 \%)$ & $0(0.0 \%)$ & 0.003 \\
\hline
\end{tabular}

Comparing between the hospital admitted and infected cases in MUI, among the 16 Norovirus positive cases more than $68 \%$ (11 cases) $(\mathrm{p}=0.1)$, similarly among the 11 Rotavirus positive cases more than $90 \%$ (10 cases) $(\mathrm{p}=0.006)$ and among 9 Adenovirus positive cases $100 \%$ ( 9 cases) $(\mathrm{p}=0.003)$ needed hospital admission [Table 3].

The mean hospital stay was $1.1 \pm 1.7$ days and $1.3 \pm 1.8$ days in DH and MUI respectively.

In $\mathrm{DH}$ more than $90 \%$ (60 cases) of Rotavirus positive cases had the hospital stay of less than 3 days with the maximum of 9 days in 1 case, whereas all the Adenovirus positive cases had the hospital stay of less than 3 days with the maximum of 3 days in 3 cases. The mean duration of hospital stays for Rotavirus and Adenovirus positive cases were 1.7 days and 1.5 days respectively.

In MUI 75\% (12 cases) of Norovirus positive cases had the hospital stay of less than 3 days with the maximum of 7 days in 2 cases, more than $72 \%$ (8 cases) of Rotavirus positive cases had the hospital stay of less than 3 days with the maximum of 5 days in 3 cases, whereas all the Adenovirus positive cases (9 cases) had the hospital stay of less than 3 days with the maximum of 3 days in 2 cases. The mean duration of hospital stays for Norovirus,
Rotavirus and Adenovirus positive cases were 2.6 days, 2.8 days and 2.0 days respectively.

Intravenous (IV) fluids were needed in $26 \%$ and $40 \%$ of cases in DH and MUI respectively. Zinc supplementation was given in 69\% cases in $\mathrm{DH}$. Eighteen percent cases were treated with oral antibiotics in $\mathrm{DH}$. No antibiotics were found to be used in MUI. No anti-diarrhoeal, antisecretary or anti-motility drugs were used in both the institution.

\section{Discussion}

Children under 5 years presented with acute onset of diarrhoea with or without nausea and vomiting seen in outpatient, emergency and those admitted in inpatient paediatric department of DH and MUI meeting the inclusive criteria were enrolled in the study. Their clinical presentation and the common cause of acute childhood diarrhoea in the two institutions were studied and compared.

Incidence of diarrhoea was found to be more in males $(69 \%)$ in $\mathrm{DH}$, while there was no significant difference in sex of patients of diarrhoea in MUI. Since this study was a hospital based study, the culture of male preference may have played some role for possible increase number of hospital visits for a male child in $\mathrm{DH}$. This result was also supported by a similar study of diarrhoea done among children in eastern Nepal, where incidence of diarrhoea was seen more in male children (67.5\%) [13]. The explanation to this male predominance remains unclear, and this difference bears no statistical significance.

In this study the highest number of diarrhoeal cases were found in children less than 12 months in both DH (48\%) and MUI (45\%), followed by 13 to 24 months age group (DH 29\%, MUI $28 \%$ ) and the number of diarrhoeal cases decreased thereafter. In a similar study of diarrhoea done among children in eastern Nepal, majority $(70.9 \%)$ of diarrhoea were observed in patients between 6 months and 2 years of age [13]. The same picture of age predisposition was observed in studies from Bangladesh [14, 15] and India [16], similarly also from studies done among children in America [17]. The young age, inadequate breastfeeding, malnutrition, low socioeconomic status, poor maternal literacy, poor sanitation and hygiene practices of the mother including poor handling of water at the household level, indiscriminate stool disposal by the mothers and lack of hand-washing before feeding their children may be associated with a 
higher incidence of diarrheal diseases in children below 24 months of age.

In developed countries like Austria, acute childhood diarrhoea is a common reason for presentation to general practice or emergency departments and for admission to hospital. In this study the mean duration of illness prior presenting to hospital was 3.2 days and 1.7 days in $\mathrm{DH}$ and MUI respectively. Children with diarrhoea in MUI were found to be brought significantly earlier to the hospital than $\mathrm{DH}$. Ninety six percent of children were brought within 3 days of illness in MUI, whereas only $32 \%$ were brought within 3 days of illness in $\mathrm{DH}(\mathrm{p}=0.001)$. The easy accessibility, better living standard and higher educational level of the parents in addition to the well-developed health insurance system in the country may be the contributing factors for the early presentation of diarrhoeal cases in MUI. Most of the complications associated with gastroenteritis are related to delays in diagnosis and delays in the institution of appropriate therapy. Without early and appropriate rehydration, many children with acute diarrhoea would develop dehydration with associated complications [18].

Although most children with gastroenteritis do not require admission to hospital, many are treated as inpatients each year. Once admitted they often remain in the hospital for several days. This is a significant burden for the health services [19]. Admission also carries a serious risk of spread to other children in the hospital, some of whom may be highly vulnerable as a consequence of their own medical conditions [20]. In this study in DH, 25\% cases had signs of dehydration among which $5 \%$ were severely dehydrated, whereas in MUI 26\% had some dehydration; however, no cases with severe dehydration were seen in MUI. In both DH and MUI majority of children having dehydration was found to be below 24 months of age (DH $80 \%$, MUI 84.6\%). Similarly, in both institution most of the children having history of fever were also below 24 months of age (DH $77.8 \%$, MUI $80 \%)$. More number of diarrhoeal cases were found to be admitted in MUI (52\%) compared to $\mathrm{DH}(37 \%)(\mathrm{p}=0.03)$. Among the children who needed admission majority were below 24 months of age in both the institutions (DH 77\%, MUI 73\%). The significant number of diarrhoeal cases being admitted in MUI may be due to the fact that the parents are more concerned about their child's health and also may be because of the better health insurance system in the country. Seven percent cases needed PICU care in DH. However no cases needed PICU care in MUI. No deaths were seen in both the institutions due to diarrhoea during the study period.

In this study in $\mathrm{DH}$, majority of stool samples tested positive for Rotavirus (66\%) followed by Adenovirus (13\%), whereas in MUI stool samples were tested positive for Norovirus (16\%) followed by Rotavirus (11\%) and Adenovirus (9\%). Most of the infected cases were below 24 months of age, which was similar to other studies. Majority of infected cases were found to have no signs of dehydration. Bresee $\mathrm{J}$ et al in 2004 concluded in the first Report from the Asian Rotavirus Surveillance Network that $45 \%$ of acute diarrheal hospitalizations in children less than 5 years of age were due to Rotavirus [21]. Study done among children in eastern Nepal showed rota antigen in $38.7 \%$ samples [13]. The large number of Rotavirus positive cases detected in our study may also be due to the fact that the study was carried out during the winter months when we expect more numbers of Rotavirus diarrhoea in the community.

In this study, majority of children were managed with Low Osmolality Rehydration Solution (ORS) in both the institutions. IV fluids were needed in $26 \%$ and $40 \%$ of cases in $\mathrm{DH}$ and MUI respectively. Zinc supplementation was also given in majority of cases $(69 \%)$ in $\mathrm{DH}$. Minority of cases $(18 \%)$ were treated with oral antibiotics in DH. However, antibiotics were found to be used in $29 \%$ of children prior to presentation to the hospital in $\mathrm{DH}$, some of which were continued during the illness. No anti-diarrhoeal, anti-secretary or anti-motility drugs were used in both the institution. No antibiotics were found to be used in MUI. There is strong evidence that zinc supplementation in children with diarrhoea in developing countries leads to reduced duration and severity of diarrhoea and could potentially prevent a large proportion of cases from recurring [18].

Many developing countries struggle with huge disease burdens of diarrhoea where a wider approach to diarrhoea prevention may be required. Preventive strategies may be of relevance to both developed and developing countries [18]. Promotion of exclusive breastfeeding, improved complementary feeding practices, improved water and sanitary facilities, promotion of personal and domestic hygiene along with Rotavirus immunization must be reinforced. 
In 1998, a quadrivalent Rhesus Rotavirusderived vaccine was licensed in the United States but subsequently withdrawn due to an increased risk of intussusceptions. Subsequent development and testing of newer Rotavirus vaccines have led to their introduction in most developed countries and approval by the WHO in 2009 for widespread use in developing countries. Emerging evidence indicates that the introduction of these vaccines is associated with a significant reduction in severe diarrhoea and associated mortality [18]. Since July 2007 oral Rotavirus vaccination is part of the routine vaccination program in Austria. Prior to vaccination nearly 1 in 60 children younger than 2 years of age, was hospitalised because of Rotavirus gastroenteritis in Austria. The immunization status for age according to the Expanded Programme on Immunization (EPI) was completed in all the children (100\%) enrolled in this study in DH which highlights the success of National Immunization Programme in Nepal. During the study period EPI schedule in Nepal did not include Rotavirus vaccine which is one of the major causes of acute diarrhoea in children. In this study Rotavirus was detected in significant number of cases in $\mathrm{DH}$ $(66 \%)$, whereas only $11 \%$ of cases were detected in MUI $(p=0.001)$. This shows that Rotavirus vaccination plays a major role in reducing childhood diarrhoea. A safe and an effective Rotavirus vaccine would have a major effect on reducing diarrhoea mortality in developing countries like Nepal. Difference in Rotavirus genotypes are seen emerging in various communities. There are limited studies describing the distribution of Rotavirus strains in our community. Our understanding of transmission and prevention of childhood diarrhoeal disease would be incomplete without studies that investigate Rotavirus strains circulating in the community.

The main limitation of the study was its hospital based study, limited sample size and limited laboratory facilities. As the study was conducted in a tertiary care hospital mostly the severe cases or those who can afford were referred or brought to the hospital. Most of the simple cases of diarrhoea are treated locally at home or at the local health facility. Several different groups of viruses have been shown to be responsible for high incidence of acute viral gastroenteritis among children during their first few years of life. Rotavirus and Adenovirus are the most important causes of early childhood gastroenteritis in both developed and developing countries, but concerning the limitation of our study other groups of viruses could not be identified and characterization of their different strains and genotypes could not be attempted due to lack of facilities. Seasonal variation of diarrhoeal cases could not be assessed due to specified time constraints of the study. However, the differences in detection rates could also be partially attributed to the study design which was conducted in different time interval in two different places and generalizability of the data in two different institutions. These limitations have to be kept in mind when interpreting and discussing the results of the study.

\section{Conclusions}

Viral diarrhoea is still the most common cause of childhood diarrhoea in developed and developing countries. Interventions should concentrate on children less than 24 months of age, where disease is most common. An environmental health education program, along with water supply and sanitation intervention, may be an effective mitigation measure to reduce diarrheal diseases in Nepal. Most children are not dehydrated and can be managed using low osmolality ORS at home or in primary health care centres. Rotavirus is still the most common cause of acute gastroenteritis in developing countries like Nepal and vaccination will have a major impact on disease rates, morbidity, and mortality. The result of this study will help us to understand the etiology of the increasing childhood diarrhoea in the surrounding community, and also guide us in the further management of viral diarrhoea and to think about the need of a safe and an effective Rotavirus vaccine in a developing country like Nepal. More research should be focused on the issue of childhood diarrhoea and the emerging newer Rotavirus genotypes in the community.

\section{Acknowledgements}

We would like to express sincere gratitude to all the faculty members of Department of Pediatrics, Dhulikhel Hospital, Kathmandu University Hospital for their continuous support and guidance for the study. We would like to acknowledge the support received from Medical University of Innsbruck, Austria, Department of Microbiology for providing the Rotavirus and Adenovirus detection ELISA kits used in the study.

\section{Conflict of Interest}

None declared 


\section{References}

1. Control of Communicable Diseases Manual. Ministry of Health, Epidemiology and Disease Control Division 2003; 84-6.

2. Melo MC, Taddei JA, Diniz-Santos DR, May DS, Carneiro NB, Silva LR. Incidence of diarrhea: poor parental recall ability. Braz J Infect Dis. 2007; 11(6):571-9. http://dx.doi.org/10.1590/S141386702007000600009

3. Parashar UD, Gibson CJ, Bresee JS, Glass RI. Rotavirus and severe childhood diarrhea. Emerg Infect Dis 2006;12:304-6. http://dx.doi.org/10.3201/eid1202. 050006

4. Greenwood D, Slack R.C.B. and Peutherer JF. Medical Microbiology A guide to microbial infections: Pathogenesis, immunity, laboratory diagnosis and control. 16th edition Churchill Livingstone 2002.

5. Annual Report. Department of Health Services, Ministry of Health, HMG of Nepal 2004/05.

6. Clark B, McKendrick M, A review of viral gastroenteritis, Curr Opin Infecet Dis, 2004;17:461-9. http://dx.doi.org/10.1097/0000143 2-200410000-00011

7. Gleizes $\mathrm{O}$, Desselberger U, Tatochenko V, et al., Nosocomial Rotavirus infection in European countries: a review of the epidemiology,

8. Patel MM, Widdowson MA, Glass RI, Akazawa K, Vinje J, et al. (2008) Systematic literature review of role of Noroviruses in sporadic gastroenteritis. Emerg Infect Dis 14: 1224-1231.

http://dx.doi.org/10.3201/eid1408. 071114
9. E. Simpson, S. Wittet, J. Bonilla, K. Gamazina, L. Cooley and J.L. Winkler, Use of formative research in developing a knowl- edge translation approach to Rotavirus vaccine introduction in developing countries, BMC Public Health7 (2007), 281. http://dx.doi.org/10.1186/14712458-7-281

10. Sherchand JB. Intestinal parasitic infection in Southern Nepal. Journal of Institute of Medicine 1997; 19:115-121

11. Cukor G, Blacklow N R, Human Viral Gastroenteritis. Micro. Rev. 1984;48(2):157-179

12.Schmitz, H. et al. "Worldwide epidemiology in human Adenovirus infections", J. Epidemiology, Vol 117 , pp.455-466

13. Shariff M, Deb M, Singh R. A study of diarrhoea among children in eastern Nepal with special reference to Rotavirus. Indian J Med Microbiol [serial online] 2003 [cited 2013 Feb 12];21:87-90

14. Tanaka G, Faruque AS, Luby SP, et al. Deaths from Rotavirus disease in Bangladeshi children: estimates from hospital-based surveillance. Pediatr Infect Dis J. 2007;26(11):1014-8. http://dx.doi.org/10.1097/INF.0b0 $13 \mathrm{e} 318125721 \mathrm{c}$

15. Paul SK, Kobayashi N, Nagashima $S$, et al. Phylogenetic analysis of Rotaviruses with genotypes G1, G2, G9 and G12 in Bangladesh: evidence for a close relationship between Rotaviruses from children and adults. Arch Virol. 2008; 153(11):1999-2012 http://dx.doi.org/10.1007/s00705008-0212-9
16. Khetawat D, Dutta P, Gupta S, et al. Emergence of Rotavirus G4P8 strain among children suffering from watery diarrhea in Calcutta, India. Intervirology. 2001;44(5):306-10. http://dx.doi.org/10.1159/0000500 62

17. Glass RI, Lew JF, Gangarosa RE, et al. Estimates of morbidity and mortality rates for diarrheal diseases in American children. J Pediatr. 1991;118(4 pt 2): S27-S33. http://dx.doi.org/10.1016/S00223476(05)81422-2

18. Pickering LK, Synder JD. Gastroenteritis. In: Behrman RE, Kliegman RM, Jenson HB. Nelson Textbook of Pediatrics. 18th ed. Philadelphia PA: W.B. Saunders; 2008 .

19.Lopez-de-Andres A, Jimenez-Garcia $\mathrm{R}$, Carrasco-Garrido P, et al. Hospitalizations associated with Rotavirus gastroenteritis in Spain, 2001- 2005. BMC Public Health 2008;8:109.

http://dx.doi.org/10.1186/14712458-8-109

20. Lopman BA, Reacher MH, Vipond IB, et al. Epidemiology and cost of nosocomial gastroenteritis, Avon, England, 2002 2003. Emerging Infectious Diseases 2004;10:182734 http://dx.doi.org/10.3201/eid1010. 030941

21. Bresee J. Fang ZY, Wang B, Nelson EA, Tam J, Soenarto Y, et al. First Report from the Asian Rotavirus Surveillance Network. Emerg Infect DIs. 2004 Jun;10(6);988-95. http://dx.doi.org/10.3201/eid1006. 030519 